\title{
Preparation of Isoflavone glucosides from Soy germ and $\beta$-Glucosidase from Bacillus coagulans PR03 for Isoflavone aglycones Production
}

Supakit Chaipoot ${ }^{1,2}$, Rewat Phongphisutthinant ${ }^{2,4}$, Sujinda Sriwattana ${ }^{1}$, Sakaewan Ounjaijean ${ }^{3}$, and Pairote Wiriyacharee ${ }^{1,2,4 *}$

${ }^{1}$ Division of Product Development Technology, Faculty of Agro-Industry, Chiang Mai University, Chiang Mai 50100, Thailand

${ }^{2}$ Science and Technology Research Institute of Chiang Mai University, Chiang Mai 50200, Thailand

${ }^{3}$ Research Institute for Health Sciences of Chiang Mai University, Chiang Mai 50200, Thailand

${ }^{4}$ Center of Excellence in Microbial Diversity and Sustainable Utilization, Faculty at Science, Chiang Mai University, Chiang Mai 50200, Thailand

*Corresponding author. E-mail: pairote.w@cmu.ac.th

https://doi.org/10.12982/CMUJNS.2019.0032

Received: December 21, 2018

Revised: March 27, 2019

Accepted: April 5, 2019

\section{ABSTRACT}

This research optimized isoflavone aglycones production from soy germ. The processes included isoflavone glucosides extraction from soy germ to use as a precursor for isoflavone aglycones production. $\beta$-glucosidase was produced from $B$. coagulans PRO3 and used to convert glucosides form to aglycones. For the B-glucosidase production using Plackett and Burman Design $(n=8)$ and $2^{2}$ factorial experiment with central composite design, the suitable medium containing peptone (2.00\%), beef extract (14.84\%), glucose (2.00\%) and magnesium sulphate (0.10\%) with $\mathrm{pH} 7.96$ was used and incubated at $30{ }^{\circ} \mathrm{C}$. The resulting $\beta$-glucosidase activity was $4.01 \mathrm{mU} / \mathrm{ml}$. However, the isoflavone glucosides was extracted by use of soy germ in $80 \%$ ethanol at a ratio of $1: 5$ with high power ultrasonication technique at $80^{\circ} \mathrm{C}$ for 160 min using a completely randomized design. The extracted isoflavone glucosides contained daidzin, genistin and glycitin of 307.47, 214.84 and 73.63 mg/100 g. (dry basis), respectively. Finally, isoflavone aglycones production 
was optimized using $2^{2}$ factorial experiment with central composite design, the total isoflavone glucosides $(595.95 \mathrm{mg} / 100 \mathrm{~g}$. dry basis) was convert to isoflavone aglycones $(112.90 \mu \mathrm{g} / \mathrm{ml})$ by $\beta$-glucosidase at $37.5^{\circ} \mathrm{C}$ for 120 hours.

Keywords: Isoflavone aglycones, Isoflavone glucosides, Soy germ, $\beta$-glucosidase, B. coagulans PR03

\section{INTRODUCTION}

The significance of healthy food consumption has become more prominent as many consumers are gaining more awareness of good eating habit such as eating more fruits and vegetables. It is known that bioactive compounds in those foods can reduce the risk of many severe diseases such as cardiovascular diseases, diabetes and cancers (Crozier et al., 2009). One of the most acknowledged bioactive compounds is isoflavone. It is a secondary metabolite from the plant with a limited taxonomic distribution such as soybean (Glycine max). Isoflavones have been associated with biological properties such as estrogenic and anti-estrogenic activities against hypocholesterolemia (Murphy, 1982), atherosclerosis, osteoporosis, anti-carcinogenic activity against breast cancer (Ohta et al., 2002) and reduced hot flush in postmenopausal women (Han et al., 2002). It can bind with estrogen receptors, and it is known as phytoestrogen (Sarkar et al., 2002). Suggested dosage of isoflavone consumption is approximately 18-20 mg for one serving size (4 time to $80 \mathrm{mg} /$ day) (Barnes et al., 1995).

The isoflavones in soybean are generally in forms of glucosides (daidzin, genistin, glycitin) more than aglycones (daidzein, genistein and glycitein). The whole soybean seed contains only $2 \%$ soy germ, and the highest quantity of isoflavones is found in the soy germ. Isoflavones found in soy germ are 5-6 times higher than the other parts, for instance, seed coat and cotyledon (Nahas et al., 2004). There is an investigation of isoflavone and antioxidant activity in cotyledon, seed coat and soy germ from four varieties of soybean. It was found that the total isoflavones in cotyledon, seed coat and soy germ were 2.73-9.71, 5.56-16.94 and 27.76-81.43 mg/ fresh weight, respectively (Yue et al., 2009).

Isoflavone is a flavonoid substance that is soluble in various polar solvents. Wiriyacharee et al. (2012) studied the extraction of isoflavone from soy germ with different solvents: water, ethanol, methanol, acetone and acetonitrile. It was found that the isoflavone glucosides was efficiently extracted with polar solvents from aqueous acetone and acetonitrile. It can be seen that isoflavones is well soluble. Moreover, high power ultrasonic technique allows polar solvents to easily penetrate extracted materials by destroying the plant cell membrane. The technique can reduce the time of the extraction with 
significantly higher yield. Ultrasound causes cavitation, which is a process that occurs in the middle of ultrasound sound wave by chemical and physical changes due to the bubbles that are produced by the compression and decompression in the liquid. Rostagno et al. (2002) investigated the effect of extraction of isoflavones from frozen soybeans compared to conventional extraction and ultrasonic extraction. It was found that the optimal condition for extraction of isoflavones was using ultrasound with $50 \%$ ethanol solution at $60{ }^{\circ} \mathrm{C}$ for $20 \mathrm{~min}$.

Large molecular size of isoflavone in the glucosides form usually slows the absorption rate in the human body. However, soybean fermentation process can reduce the molecular size of the glucosides to aglycones by $\beta$-glucosidase. Previous investigations show that $\beta$-glucosidases from various microorganisms such as Aspergillus oryzae (Horii et al., 2009), Bacillus subtilis (Kuo and Lee, 2008), Bifidobacterium lactis, Lactobacillus acidophilus, L. casei (Donkor and Shah, 2008), Escherichia coli (Ismail and Hayes, 2005), Paecilomyces thermophila (Yang et al., 2009), Pseudomonas sp. (Yang et al., 2004) Thermotoga maritima (Xue et al., 2009) and B. coagulans (Phongphisutthinant et al., 2015) were used. Especially, the source of $\beta$-glucosidases from B. coagulans PR03 is able to convert isoflavones from glucosides to aglycones (Wiriyacharee et al., 2011 and 2012) and easily isolated from Thai fermented soybean (tua-nao). Phongphisutthinant et al. (2015) reported that B. coagulans PR03 was predominant bacteria enriching isoflavone aglycones in tua-nao production. The well-absorbed structure of isoflavone aglycones would have higher potency as estrogen than isoflavone glucosides. The chemical forms of these isoflavones affect their biological activities (Izumi et al., 2000). Among them, isoflavone aglycones, especially the genistein and daidzein, exhibit higher biological activity than isoflavone glucosides (Kuo et al., 2006). Enzymatic hydrolysis especially $\beta$-glucosidase has become the method more specific than chemical hydrolysis (Song et al., 2011).

The scope of this study is to investigate the isoflavone glucosides extraction from soy germ using with ethanol in combination with ultrasonication technique. Additionally, $\beta$-glucosidases production from B. coagulans PR03 is optimized and it is applied to produce isoflavone aglycones from isoflavone glucosides. 


\section{MATERIALS AND METHODS}

\section{Materials}

Soy germ is a by-product of the tofu industry. Normally, soy germ was used in the animal feed industry. It was obtained from the tofu factory in Chiang Mai province (Chiang Mai field crop research center). Soy germ was packaged in High Density Polyethylene (HDPE) plastic bags and stored at $-18{ }^{\circ} \mathrm{C}$ until further used (not exceed 4 months storage).

\section{Isoflavone glucosides extraction}

Isoflavone glucosides were extracted from soy germ using a completely randomized design (CRD) with three replicates which were 40,60, 80\% and absolute (99.8\%) ethanol as a solvent (ratio of 1:5 by weight) with high power ultrasonication technique at high power and low frequencies (Elma Schmidbauer $\mathrm{GmbH}$, Singen, Germany) were fixed at $40 \mathrm{kHz}$ and power levels $550 \mathrm{~W} / \mathrm{cm}^{2}$ (Fan et al., 2012). The study was $2^{2}$ factorial design with 2 center points was employed. The process variables included: extraction temperature $\left(x_{1}\right)$ ranging from 30 to $80^{\circ} \mathrm{C}$; extraction time $\left(x_{2}\right)$ from 0 to 110 min were on daidzin, genistin, glycitin and total glucosides while the response variables. Lastly, the different time (60-180 $\mathrm{min})$ for isoflavone glucosides extraction were continuously examined using a completely randomized design (CRD) with three replicates (Wiriyacharee, 2012).

\section{$\beta$-Glucosidase production from B. coagulans PR03}

For $\beta$-glucosidase production, the activated condition of B. coagulans PR03 (isolated from fresh tua-nao) was investigated by inoculating the culture in $10 \mathrm{ml}$ nutrient broth and incubated at $30{ }^{\circ} \mathrm{C}$ for 24 hours. A medium development was also studied by Plackett and Burman Design $(n=8)$ which was used to identify important factors affecting $\beta$-glucosidase activity of $B$. coagulans PR03 and used to find the suitable medium for cultivation. The optimal $\beta$-glucosidase production was studied using $2^{2}$ factorial with central composite design (Wiriyacharee, 2012). The process variables included: beef extract $\left(x_{1}\right)$ from 8 to $15 \% ; \mathrm{pH}$ value $\left(x_{2}\right)$ ranging from 6 to 8 and the response variable was measured for $\beta$-glucosidases activity. B. coagulans PR03 was prepared in $90 \mathrm{ml}$ of the developed medium at $30{ }^{\circ} \mathrm{C}$ for 24 hours. Furthermore, the $\beta$-glucosidase activity was measured every 3 hours to predict the optimal harvesting time of $\beta$-glucosidase. 


\section{$\beta$-Glucosidase activity analysis}

One $\mathrm{ml}$ of inoculum was centrifuged at $12,000 \mathrm{~g}$ for $10 \mathrm{~min}$ to collected cells of B. coagulans PR03 and washed with a sodium phosphate buffer solution at $\mathrm{pH}$ 7.0. The $\beta$-glucosidases activity was measured by adding $0.5 \mathrm{mM}$ $p$-nitrophenyl-beta-D-pyranoside ( $p$-NPG) in an amount of $0.5 \mathrm{ml}$ and incubated at $37{ }^{\circ} \mathrm{C}$ for $30 \mathrm{~min}$. Finally, the reaction was stopped with $0.5 \mathrm{ml}$ of $2 \mathrm{M}$ $\mathrm{Na}_{2} \mathrm{CO}_{3}$ and measured the absorbance at $620 \mathrm{~nm}$. The $\beta$-glucosidase 1 unit was defined as the amount of enzyme required to hydrolyze $1 \mathrm{~mol}$ of p-Nitrophenol / 1 min (Fujita et al., 2010).

\section{Isoflavone aglycones production}

The production of isoflavone aglycones was investigated by extracted isoflavone glucosides solution ( $100 \mathrm{ml}), \beta$-Glucosidase from $B$. coagulans PR03 $(100 \mathrm{ml} ; 0.4$ Unit) and deionized water $(800 \mathrm{ml})$ with the ratio of $1: 1: 8$, time and temperature of isoflavone aglycones production were studied using $2^{2}$ factorial experiment with central composite design. The process variables included: production time time $\left(x_{1}\right)$ from 72 to 168 hours; production temperature $\left(x_{2}\right)$ ranging from 30 to $45^{\circ} \mathrm{C}$ and the response variables were measured for daidzein, genistein, glycitein and total aglycones. During the experiment, the solution was shaked at $200 \mathrm{rpm}$.

\section{HPLC Analysis of isoflavone glucosides and aglycones}

The analysis of isoflavones were conducted by High Performance Liquid Chromatography (HPLC) technique as per Klejdus et al., (2005) with Diode array detector (DAD) using Column from Inersil ODS3 size 250x4.6 mm., injection volume of $20 \mu \mathrm{L}$, flow rate at $1.0 \mathrm{ml} / \mathrm{min}$, mobile phase $\mathrm{A}$ as $0.1 \%$ acetic acid, mobile phase B as methanol, gradient separation at 5 min $35 \% \mathrm{~B}$, $8 \min 42 \%$ B, $22 \min 90 \%$ B, 28 min $100 \%$ B, $29.5 \operatorname{min~30\% ~B~and~held~at~}$ that level for $2.5 \mathrm{~min}$, a total run time was $32 \mathrm{~min}$, column oven at $40^{\circ} \mathrm{C}$, total run time was $32 \mathrm{~min}$ and $255 \mathrm{~nm}$. of detection wavelength and isoflavone glucosides and aglycones contents as daidzein, daidzin, glycitein, glycitin, genistein and genistin were obtained by comparison with isoflavone standards solution.

\section{Statistical Analysis}

The experimental design and result analysis particularly Plackett and Burman Design and completely randomized design (CRD) were established using SPSS 11.0 (SPSS Inc., Chicago, USA) and Design-Expert software version 7.1 (Statease Inc., Minneapolis, USA). One-way analysis of variance 
(ANOVA) and multiple-range test were used for comparison of the results. Homogenous groups and the least significant difference (LSD) at a significant level $(P \leq 0.05)$ were determined. To obtain interaction between process variables and responses, $2^{2}$ factorial design with 2 center points and central composite design were employed. The variables included: factor1 $\left(x_{1}\right)$ and factor2 $\left(x_{2}\right)$ with 2 center points. The interaction between each response and process variables were estimated by a second order polynomial equation (1). Analysis of variance (ANOVA) was also used to examined the statistical significant of the models.

$$
Y=\beta_{0}+\beta_{1} x_{1}+\beta_{2} x_{2}+\beta_{12} x_{1} x_{2}+\beta_{11} x_{1}^{2}+\beta_{22} x_{2}^{2}
$$

where $Y$ is a response, $x$ is a process variable and $\beta$ is a coefficient of the term.

\section{RESULTS}

The optimal concentration of ethanol on isoflavone glucosides extraction from soy germ

The effect of ethanol on isoflavone glucosides extraction from soy germ was examined. The result showed that $80 \%$ ethanol extract had the highest amount of isoflavone glucosides $(280.80 \mathrm{mg} / 100 \mathrm{~g}$. dry basis) (Table 1). This result coincides with a previous study of Seung et al., (2010) which demonstratedthe maximum amount of isoflavones was obtained from cotyledons $(2.18 \mathrm{mg} / \mathrm{g}$.) when extracted with $80-90 \%(\mathrm{v} / \mathrm{v})$ ethanol above $90{ }^{\circ} \mathrm{C}$ for $100 \mathrm{~min}$.

Table 1. Effect of ethanol on isoflavone glucosides extraction from soy germ.

\begin{tabular}{|c|c|c|c|c|}
\hline \multirow{2}{*}{$\begin{array}{c}\text { Concentration of } \\
\text { ethanol }(\%)\end{array}$} & \multicolumn{4}{|c|}{ Isoflavone glucosides (mg/100 g. dry basis) } \\
\hline & Daidzin & Genistin & Glycitin & $\begin{array}{l}\text { Total gluco- } \\
\text { sides }\end{array}$ \\
\hline Absolute $(99.8 \%)$ & $124.63 \pm 0.11^{\mathrm{b}}$ & $128.32 \pm 0.06^{\mathrm{b}}$ & $12.19 \pm 0.53^{\mathrm{b}}$ & $265.17 \pm 0.70^{\mathrm{b}}$ \\
\hline 80 & $130.24 \pm 0.45^{\mathrm{a}}$ & $137.59 \pm 0.49^{\mathrm{a}}$ & $16.07 \pm 1.27^{\mathrm{a}}$ & $280.70 \pm 0.43^{\mathrm{a}}$ \\
\hline 60 & $117.72 \pm 0.19^{c}$ & $121.86 \pm 0.28^{\mathrm{c}}$ & $11.57 \pm 0.53^{\mathrm{c}}$ & $251.15 \pm 0.62^{\mathrm{c}}$ \\
\hline 40 & $98.45 \pm 0.52^{\mathrm{d}}$ & $102.76 \pm 0.13^{\mathrm{d}}$ & $8.04 \pm 0.06^{\mathrm{d}}$ & $209.25 \pm 0.59^{\mathrm{d}}$ \\
\hline
\end{tabular}

Note: Different superscripts in the same column denoted by small letter are significantly different $(P \leq 0.05)$. 


\section{Effect of temperature and time on isoflavone glucosides extraction from soy germ}

The effect of temperature $\left(30-80{ }^{\circ} \mathrm{C}\right)$ and time $(0-110 \mathrm{~min})$ on the extraction efficiency of isoflavone glucosides extraction from soy germ was studied. The relationship of isoflavone glucosides with extraction time and temperature are shown in Table 2.

The statistical analysis of the results allowed fitting a coded empirical model relating daidzin (equation 2), genistin (equation 3), glycitin (equation 4) and total glucosides (equation 5) to extraction temperature and extraction time. The ANOVA analyses show a high correlation coefficient and a good performance of the $F$ test for regressions. Therefore, equation 2, 3, 4 and 5 are predictive of daidzin, genistin, glycitin and total glucosides in the investigated range of factors.

$$
\begin{aligned}
& \text { Daidzin } \quad=105.94-3.75 \text { (extraction temperature) } \quad ; \mathrm{R}^{2}=0.9766 \\
& +2.33 \text { (extraction time) }+0.02 \text { (extraction } \\
& \text { temperature)(extraction time) }+0.04
\end{aligned}
$$

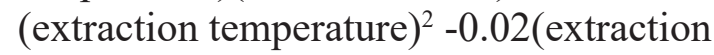

$$
\begin{aligned}
& \text { time })^{2} \\
& \text { Genistin }=133.00-4.81 \text { (extraction temperature) } \quad ; \mathrm{R}^{2}=0.9468 \\
& \text { temperature)(extraction time) }+0.04 \\
& \text { (extraction temperature) }^{2}-0.01 \text { (extraction } \\
& \text { time })^{2} \\
& \text { Glycitin }=3.07-0.11 \text { (extraction temperature) }+0.03 \\
& \text { (extraction time })+4.85 \times 10^{-4} \text { (extraction } \\
& \text { temperature)(extraction time) } \\
& \left.+1.12 \times 10^{-3} \text { (extraction temperature }\right)^{2} \\
& \left.-2.61 \times 10^{-4} \text { (extraction time) }\right)^{2} \\
& \text {; } \mathrm{R}^{2}=0.9343 \\
& \text {; } \mathrm{R}^{2}=0.9666 \\
& \text { temperature)(extraction time) } \\
& +0.09 \text { ( extraction temperature })^{2} \\
& +0.03 \text { (extraction time) })^{2}
\end{aligned}
$$


Table 2. Effects of temperature and time on isoflavone glucosides extraction from soy germ extracted with $80 \%$ ethanol.

\begin{tabular}{cccccc}
\hline \multirow{2}{*}{$\begin{array}{c}\text { Extraction } \\
\text { temperature }\end{array}$} & $\begin{array}{c}\text { Extraction } \\
\text { (ime }\end{array}$ & \multicolumn{3}{c}{ Isoflavone glucosides (mg/100g. dry basis) } \\
\cline { 3 - 6 } & $(\mathbf{m i n})$ & Daidzin & Genistin & Glycitin & $\begin{array}{c}\text { Total gluco- } \\
\text { sides }\end{array}$ \\
\hline 30 & 0 & $17.72 \pm 2.39$ & $9.00 \pm 0.39$ & $0.35 \pm 0.01$ & $27.55 \pm 3.43$ \\
80 & 0 & $59.76 \pm 2.39$ & $38.40 \pm 0.79$ & $1.36 \pm 0.15$ & $99.52 \pm 3.22$ \\
30 & 110 & $149.96 \pm 11.44$ & $104.04 \pm 1.33$ & $3.11 \pm 0.10$ & $257.11 \pm 11.78$ \\
80 & 110 & $270.23 \pm 0.18$ & $247.43 \pm 32.32$ & $6.06 \pm 0.11$ & $523.72 \pm 32.37$ \\
30 & 55 & $122.74 \pm 0.89$ & $115.33 \pm 12.20$ & $2.54 \pm 0.01$ & $240.61 \pm 11.39$ \\
80 & 55 & $189.09 \pm 1.51$ & $148.14 \pm 6.46$ & $3.45 \pm 0.01$ & $340.68 \pm 4.95$ \\
55 & 0 & $43.07 \pm 4.16$ & $31.88 \pm 6.67$ & $0.89 \pm 0.01$ & $75.84 \pm 10.83$ \\
55 & 110 & $157.68 \pm 1.87$ & $130.29 \pm 10.00$ & $2.86 \pm 0.08$ & $290.83 \pm 11.90$ \\
55 & 55 & $128.34 \pm 0.28$ & $92.45 \pm 0.70$ & $2.43 \pm 0.01$ & $223.22 \pm 0.99$ \\
55 & 55 & $128.44 \pm 0.39$ & $86.92 \pm 0.81$ & $2.55 \pm 0.01$ & $217.90 \pm 0.85$ \\
\hline
\end{tabular}

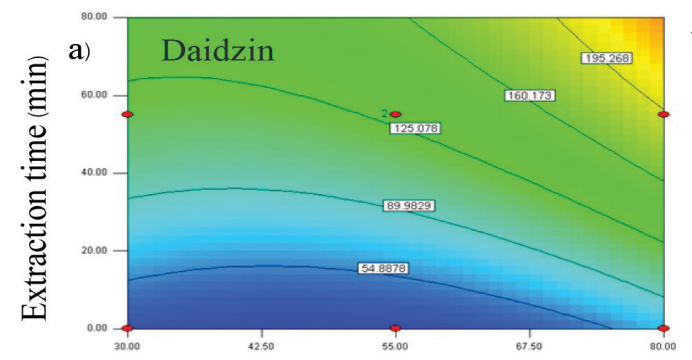

Extraction temperature $\left({ }^{\circ} \mathrm{C}\right)$

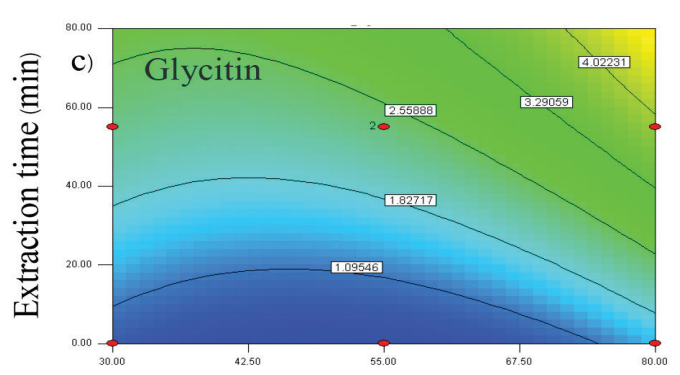

Extraction temperature $\left({ }^{\circ} \mathrm{C}\right)$

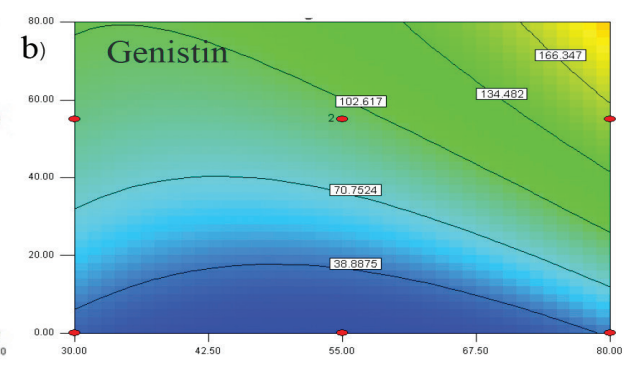

Extraction temperature $\left({ }^{\circ} \mathrm{C}\right)$

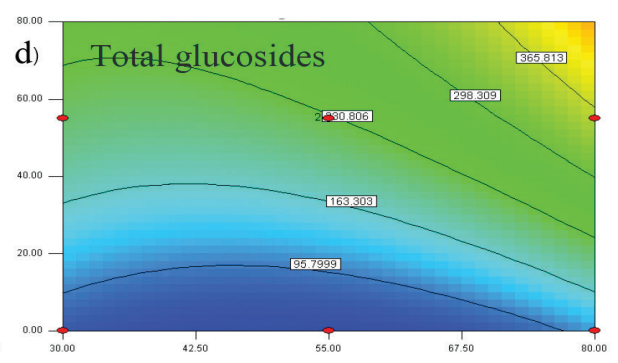

Extraction temperature $\left({ }^{\circ} \mathrm{C}\right)$

Figure 1. Response surfaces of the correlation between extraction time and temperature on a) Daidzin, b) Genistin, c) Glycitin and d) Total glucosides. 
The response surfaces for daidzin, genistin, glycitin and total glucosides, are shown in Figure 1. This surface indicates that the conditions that maximize yield are $80{ }^{\circ} \mathrm{C}$ and $110 \mathrm{~min}$. It is also shows an interaction between extraction temperature and time. With the increasing extraction time the amounts of daidzin, genistin, glycitin and total glucosides are increased. Therefore, the extraction temperature should be $80{ }^{\circ} \mathrm{C}$ and the further extraction time should be continuously investigated.

\section{Effect of time on isoflavone glucosides extraction from soy germ}

The results in Table 3 show that an extraction time of $160 \mathrm{~min}$ could extract the maximum amount of isoflavone glucosides $(595.93 \mathrm{mg} / 100 \mathrm{~g}$. dry basis). It could be concluded that the suitable extraction condition for isoflavone glucosides from soy germ was the high power ultrasonication technique with $80 \%$ ethanol at $80{ }^{\circ} \mathrm{C}$ for $160 \mathrm{~min}$. This trend was similarly observed in the previous study, $90^{\circ} \mathrm{C}$ for $100 \mathrm{~min}$ (Wiriyacharee et al., 2012).

Table 3. Effect of time on isoflavone glucosides extraction from soy germ by $80 \%$ ethanol at $80{ }^{\circ} \mathrm{C}$.

\begin{tabular}{ccccc}
\hline \multirow{2}{*}{ Time (min) } & \multicolumn{4}{c}{ Isoflavone glucosides (mg/100g. dry basis) } \\
& Daidzin & Genistin & Glycitin & Total glucosides \\
\hline 60 & $196.55 \pm 0.11^{\mathrm{f}}$ & $139.32 \pm 0.21^{\mathrm{g}}$ & $45.09 \pm 0.44^{\mathrm{g}}$ & $380.96 \pm 0.20^{\mathrm{g}}$ \\
80 & $216.28 \pm 2.89^{\mathrm{e}}$ & $152.83 \pm 0.31^{\mathrm{f}}$ & $49.51 \pm 0.22^{\mathrm{f}}$ & $418.61 \pm 2.42^{\mathrm{f}}$ \\
100 & $243.58 \pm 3.85^{\mathrm{d}}$ & $166.72 \pm 0.84^{\mathrm{e}}$ & $54.13 \pm 0.09^{\mathrm{e}}$ & $464.44 \pm 4.36^{\mathrm{e}}$ \\
120 & $262.87 \pm 0.23^{\mathrm{c}}$ & $186.34 \pm 0.14^{\mathrm{c}}$ & $62.25 \pm 0.82^{\mathrm{c}}$ & $511.45 \pm 0.96^{\mathrm{c}}$ \\
140 & $268.80 \pm 0.89^{\mathrm{b}}$ & $190.73 \pm 0.59^{\mathrm{b}}$ & $63.75 \pm 0.48^{\mathrm{b}}$ & $523.28 \pm 1.87^{\mathrm{b}}$ \\
160 & $307.47 \pm 0.64^{\mathrm{a}}$ & $214.84 \pm 0.40^{\mathrm{a}}$ & $73.63 \pm 0.08^{\mathrm{a}}$ & $595.93 \pm 1.09^{\mathrm{a}}$ \\
180 & $245.16 \pm 0.36^{\mathrm{d}}$ & $171.12 \pm 0.21^{\mathrm{d}}$ & $58.46 \pm 0.06^{\mathrm{d}}$ & $474.74 \pm 0.62^{\mathrm{d}}$ \\
\hline
\end{tabular}

Note: Different superscript in the same column denoted by small letter are significantly different $(P \leq 0.05)$.

Study on medium formulation and condition for $\beta$-glucosidase production by $B$. coagulans PR03

Plackett and Burman Design $(n=8)$ was used to screen factors affecting $\beta$-glucosidase activity of $B$. coagulans PR03. Table 4 shows that beef extract and $\mathrm{pH}$ were significant factors that positively affected $\beta$-glucosidase activity. Thus, they were optimized in the next experiment while other factors were fixed 
according to their effect. The factor with positive impact such as magnesium sulfate was fixed at a high level. On the other hand, negative impact factors including peptone, glucose and temperature were fixed at a low level.

Table 4. Effect of cultivation factors on $\beta$-glucosidase activity of $B$. coagulans PR03.

\begin{tabular}{lcccc}
\hline \multicolumn{1}{c}{ Factors } & Low level & High level & \multicolumn{2}{c}{$\begin{array}{c}\boldsymbol{\beta} \text {-glucosidase activity } \\
(\mathbf{m U} / \mathbf{m l})\end{array}$} \\
\cline { 5 - 6 } & $(-)$ & $(+)$ & Effect & Calculate-test \\
\hline $\mathrm{A}=$ Beef extract $(\%)$ & 2.00 & 10.00 & 0.010 & $3.536^{*}$ \\
$\mathrm{~B}=$ Peptone $(\%)$ & 2.00 & 10.00 & -0.003 & -1.179 \\
$\mathrm{C}=$ Magnesium sulfate $(\%)$ & 0.02 & 0.10 & 0.009 & 3.071 \\
$\mathrm{D}=$ Glucose $(\%)$ & 2.00 & 6.00 & -0.001 & -0.500 \\
$\mathrm{E}=\mathrm{pH}$ & 5.00 & 7.00 & 0.016 & $5.500^{*}$ \\
$\mathrm{~F}=$ Temperature $\left({ }^{\circ} \mathrm{C}\right)$ & 30.00 & 50.00 & -0.004 & -1.393 \\
\hline
\end{tabular}

Note: * significantly different with $80 \%$ confident interval $(\mathrm{t}$-table $=3.078)$.

\section{Study on optimal conditions affecting the $\beta$-glucosidase production from screened factors}

The results from Table 4 showed that beef extract and $\mathrm{pH}$ affected on $\beta$-glucosidase activity. The effects of beef extract and $\mathrm{pH}$ were further examined and the results are shown in Table 5.

The statistical analysis of the results allowed fitting a coded empirical model relating $\beta$-glucosidase activity (equation 6) to extraction temperature and time. The ANOVA analyses showed a high correlation coefficient and a good performance of the $F$ test for regressions. Equation 6 is predictive of $\beta$-glucosidase activity in the investigated range of factors.

$$
\begin{aligned}
\beta \text {-glucosidase activity }= & -25.38-0.68(\text { beef extract }) \quad ; \mathrm{R}^{2}=0.9577 \\
& +7.96(\mathrm{pH}) \\
& +0.20(\text { beef extract })(\mathrm{pH}) \\
& -0.03(\text { beef extract })^{2}-0.66(\mathrm{pH})^{2}
\end{aligned}
$$


Table 5. The $\beta$-glucosidase activities from varied beef extract and $\mathrm{pH}$ value.

\begin{tabular}{ccc}
\hline Beef extract $\mathbf{( \% )}$ & $\mathbf{p H}$ value & $\boldsymbol{\beta}$-glucosidase activity $(\mathbf{m U} / \mathbf{m l})$ \\
\hline 9.03 & 6.29 & 1.68 \\
13.97 & 6.29 & 1.74 \\
9.03 & 7.71 & 2.35 \\
13.97 & 7.71 & 3.80 \\
8.00 & 7.00 & 2.15 \\
15.00 & 7.00 & 2.53 \\
11.50 & 6.00 & 0.92 \\
11.50 & 8.00 & 3.09 \\
11.50 & 7.00 & 2.87 \\
11.50 & 7.00 & 2.67 \\
\hline
\end{tabular}

Note: The $\beta$-Glucosidase 1 unit was defined as the amount of enzyme required to hydrolyze $1 \mathrm{~mol}$ of $P$ - Nitrophenol / $1 \mathrm{~min}$.

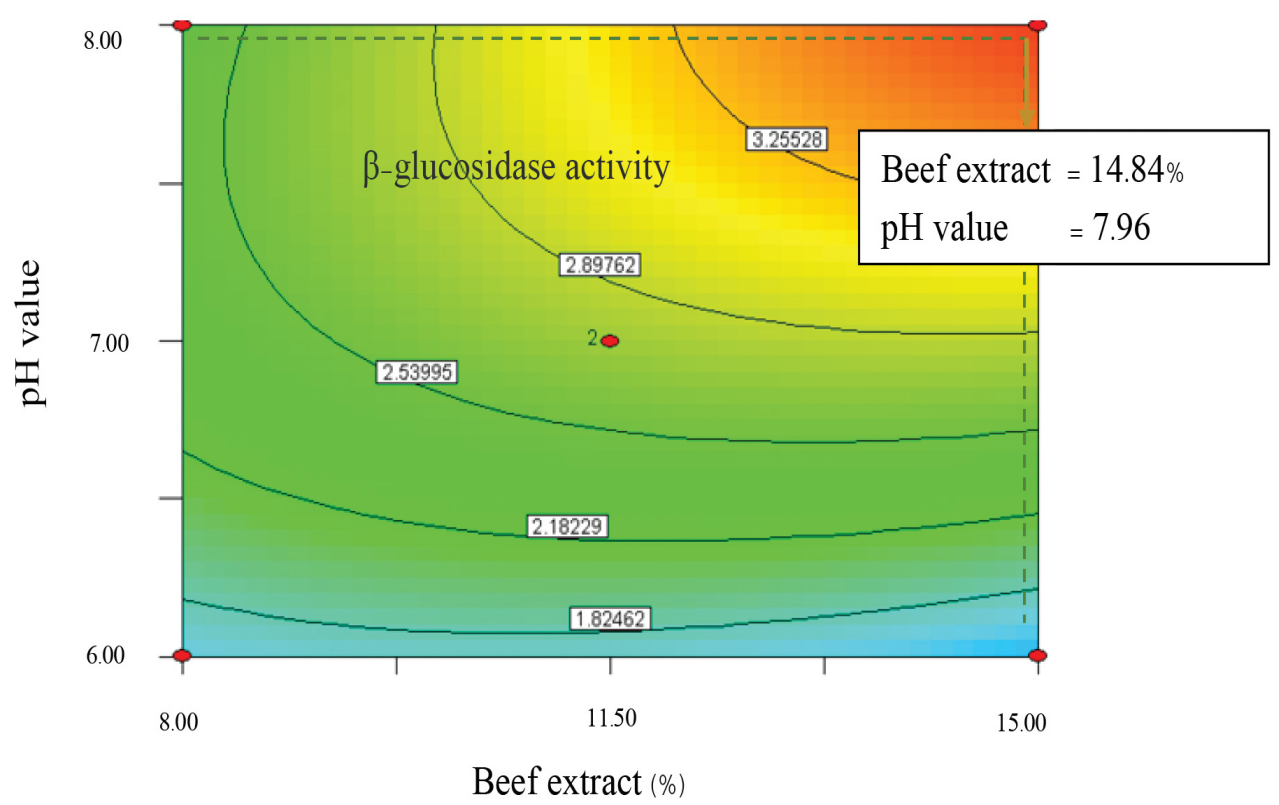

Figure 2. Response surface of the correlation between beef extract and $\mathrm{pH}$ value on $\beta$-glucosidase activity. 
From the equation 6 and Figure 2, the predicted optimal model showed that the optimal condition for $B$. coagulans PR03 cultivation was beef extract $14.84 \%$ with the fixed level of $2.00 \%$ peptone, $2.00 \%$ glucose and, $0.10 \%$ magnesium sulfate, then incubated at $30{ }^{\circ} \mathrm{C}$ and $\mathrm{pH}$ 7.96. However, the suitable harvesting time for the highest $\beta$-glucosidase activity from $B$. coagulans PR03 was 18 hours with the maximum activity of $4.01 \mathrm{mU} / \mathrm{ml}$ (Figure 3).

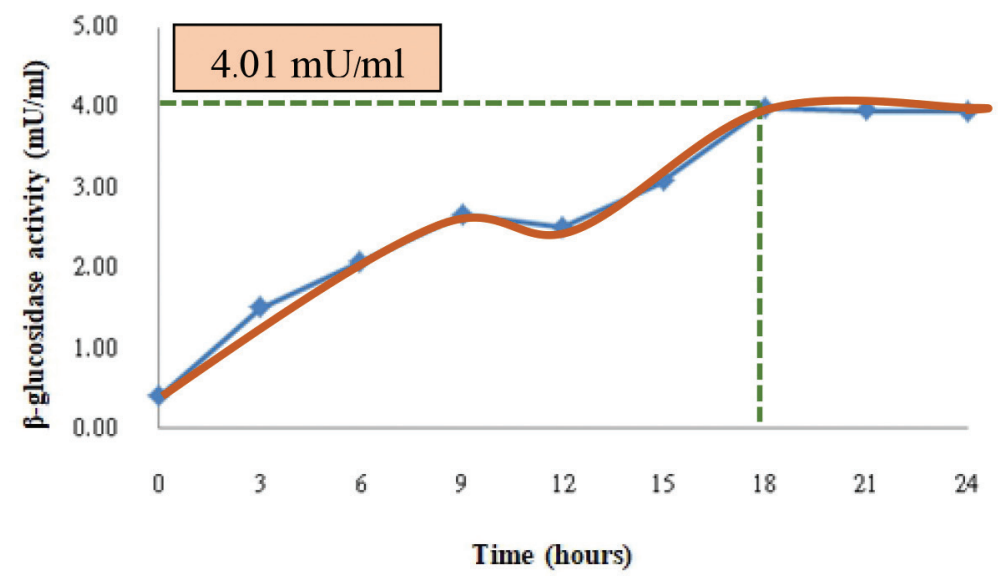

Figure 3. $\beta$-glucosidase activity at different incubation time.

The optimal time and temperature of isoflavone aglycones production using $\beta$-glucosidase from $B$. coagulans PR03

Isoflavone glucosides preparing from soy germ using high power ultrasonication technique with $80 \%$ ethanol at $80{ }^{\circ} \mathrm{C}$ for 160 min was applied as a substrate for isoflavone aglycones production. It was necessary to use the $\beta$-glucosidase from $B$. coagulans PR03 in order to convert to aglycone form.

The equations 7, 8, 9 and Figure 4 show that the amounts of daidzein, glycitein and total isoflavone aglycones were depended on production time, temperature and interaction between production time and temperature. Increasing production time and temperature, the amount of daidzein, glycitein and total isoflavone aglycones were increased but genistein was not significantly affected $(P \leq 0.05)$. Therefore, the suitable time and temperature for isoflavone aglycones production could be 120 hours and $37.50{ }^{\circ} \mathrm{C}$ with the total isoflavone aglycones of $112.90 \mu \mathrm{g} / \mathrm{ml}$. 
Daidzein

$$
\begin{aligned}
= & -759.20+1.78 \text { (production time) } \\
& +39.59 \text { (production temperature) } \\
& -0.02 \text { (production time) (production } \\
& \text { temperature) }-0.004 \text { (production } \\
& \text { time) } \left.)^{2}-0.53 \text { (production temperature) }\right)^{2}
\end{aligned}
$$$$
\mathrm{R}^{2}=0.8515
$$

Glycitein

$$
\begin{aligned}
= & -224.70+0.88 \text { (production time) } \\
& +12.9 \text { (production temperature) } \\
& -0.02 \text { (production time) (production } \\
& \text { temperature)- } 0.003 \text { (production time) }{ }^{2} \\
& -0.18 \text { (production temperature) }{ }^{2}
\end{aligned}
$$$$
\mathrm{R}^{2}=0.8554
$$

Total

$$
=-921.19+2.64 \text { (production time) }
$$$$
\mathrm{R}^{2}=0.8210
$$

aglycones

- 50.45(production temperature)

- 0.02(production time)(production temperature) -0.007 (production time) $)^{2}$

- 0.69(production temperature) $)^{2}$

Table 6. Effect of time and temperature on isoflavone aglycones production using $\beta$-glucosidase from $B$. coagulans PR03.

\begin{tabular}{cccccc}
\hline \multirow{2}{*}{$\begin{array}{c}\text { Production } \\
\text { time (hours) }\end{array}$} & $\begin{array}{c}\text { Production } \\
\text { temperature }\end{array}$ & \multicolumn{4}{c}{ Isoflavone aglycones $(\boldsymbol{\mu g} / \mathbf{m l})$} \\
\cline { 3 - 6 } & $\left.{ }^{\mathbf{}} \mathbf{C}\right)$ & Daidzein & Genistein & Glycitein & $\begin{array}{c}\text { Total } \\
\text { aglycones }\end{array}$ \\
\hline 86.06 & 32.2 & $30.79 \pm 0.18$ & $42.12 \pm 0.72$ & $12.36 \pm 0.12$ & $85.27 \pm 0.35$ \\
153.94 & 32.2 & $43.71 \pm 0.13$ & $45.68 \pm 0.15$ & $16.45 \pm 0.28$ & $105.84 \pm 0.11$ \\
86.06 & 42.8 & $10.64 \pm 1.07$ & $29.87 \pm 3.21$ & $6.07 \pm 0.41$ & $46.57 \pm 0.21$ \\
153.94 & 42.8 & $11.25 \pm 0.12$ & $31.80 \pm 1.02$ & $9.40 \pm 0.16$ & $52.44 \pm 0.32$ \\
72 & 37.5 & $45.42 \pm 0.13$ & $43.81 \pm 3.78$ & $16.61 \pm 2.91$ & $105.84 \pm 0.75$ \\
168 & 37.5 & $50.81 \pm 0.21$ & $46.65 \pm 1.37$ & $13.48 \pm 2.46$ & $110.94 \pm 0.88$ \\
120 & 30 & $45.02 \pm 0.34$ & $51.24 \pm 0.52$ & $19.89 \pm 0.66$ & $116.15 \pm 0.45$ \\
120 & 45 & $11.93 \pm 0.06$ & $33.02 \pm 0.65$ & $11.16 \pm 0.18$ & $56.11 \pm 0.12$ \\
120 & 37.5 & $51.26 \pm 0.81$ & $50.28 \pm 0.81$ & $12.33 \pm 0.20$ & $113.88 \pm 0.65$ \\
120 & 37.5 & $51.31 \pm 0.06$ & $48.45 \pm 0.09$ & $12.15 \pm 0.08$ & $111.92 \pm 0.33$ \\
\hline
\end{tabular}



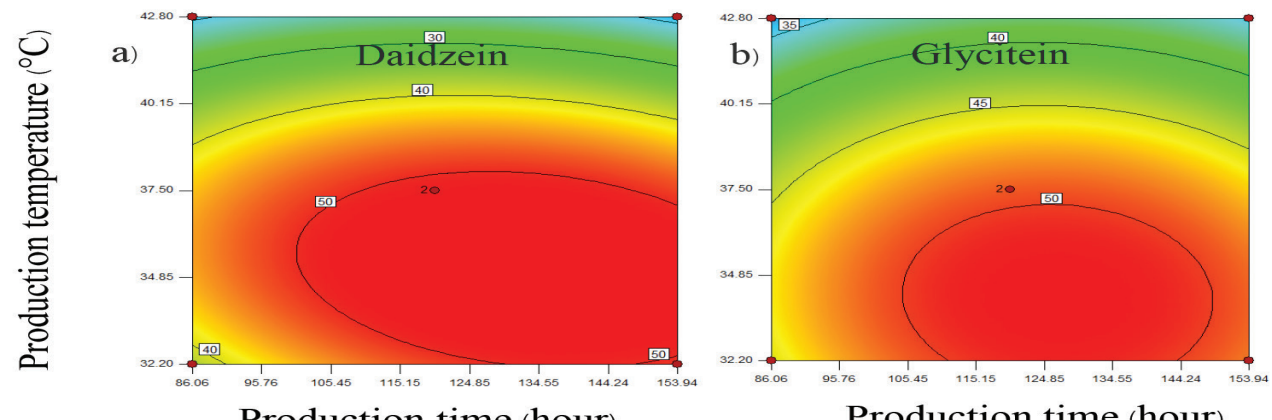

Production time (hour)

Production time (hour)

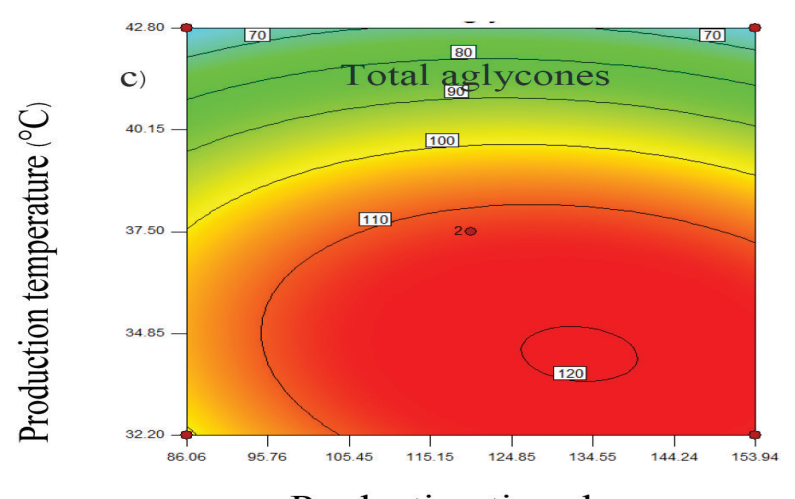

Production time (hour)

Figure 4. Response surfaces of the correlation between production time and temperature on a) Daidzein b) Glycitein and c) Total aglycones.

\section{DISCUSSION}

In this research, soy germ was used as a precursor of isoflavone aglycones production because of rich isoflavone glucosides content (Nahas et al., 2004) and a by-product of the tofu industry. Isoflavone glucosides can be extracted using other polar solvents, such as acetone, acetonitrile and methanol (Wiriyacharee et al., 2012). However, from the safety consumption point of view, this research selected ethanol as main extracting solvent with high power ultrasonication. According to Mauricio et al. (2003) reported isoflavone extraction by ultrasonication gave better results than mix-stiring technique and at a low cost, low toxicity and eco-friendly.

For $\beta$-glucosidase from B. coagulans PR03 were used incubation $\mathrm{pH}$ and temperature at 7.96 and $30^{\circ} \mathrm{C}$. Similar to reported of Zehranur et al. (2017) $\beta$-glucosidase belonging to the strains (L. rhamnosus EA1 and L. casei SC1) exhibited high $\beta$-glucosidase activity at $\mathrm{pH} 7.5$ and an optimum temperature at $30{ }^{\circ} \mathrm{C}$. 
The isoflavone aglycones were able to produce using isoflavone glucosides with $\beta$-glucosidase from $B$. coagulans PR03. According to Park et al. (2003) reported that $\beta$-glucosidase from Paenibacillus xylanilyticus KJ-03 was capable of hydrolyzing isoflavone daidzin and genistin. Moreover, the application of $\beta$-glucosidase and its immobilization could be an alternative choice to promote the bioconversion of the isoflavone glucosides to aglycones such as chitosan was used as stationary phase for immobilized $\beta$-glucosidase (Luciana et al., 2014). Lastly, isoflavone aglycones could be applied as bioactive food ingredients for healthy products or supplement food.

\section{CONCLUSION}

The suitable method for isoflavone glucosides extraction was high power ultrasonication using $80 \%$ ethanol at $80^{\circ} \mathrm{C}$ for $160 \mathrm{~min}$. The extraction yield of isoflavone glucosides was $595.93 \mathrm{mg} / 100 \mathrm{~g}$. dry basis. The resulting isoflavone glucosides were converted to isoflavone aglycones by $\beta$-glucosidase produced from $B$. coagulans PR03. The optimal media for cultivation of $B$. coagulans PR03 was the mixture of peptone, beef extract, glucose, and magnesium sulfate at amounts of $2.00 \%, 14.84 \%, 2.00 \%$ and $0.10 \%$, respectively. The incubation condition was at $30^{\circ} \mathrm{C}$ and $\mathrm{pH} 7.96$ for 18 hours resulting in the highest $\beta$-glucosidase activity $(4.01 \mathrm{mU} / \mathrm{ml})$. To convert isoflavone glucosides to isoflavone aglycones, 1:1:8 ratio of isoflavone glucosides, B. coagulans PR03 and deionized water were incubated at $37.50{ }^{\circ} \mathrm{C}$ for 120 hours.

\section{ACKNOWLEDGEMENTS}

The authors would like to thank the Agricultural Research Development Agency (Public Organization) for financial support. This research work was partially supported by Chiang Mai University. Our gratitude is also extended to Science and Technology Research Institute (STRI), Chiang Mai University for their facilities. 


\section{REFERENCES}

Barnes, S., Peterson. T.G., and Coward, L. 1995. Rationale for the use of genistein containing soy matrices in chemoprevention trials for breast and prostate cancer. Journal of Cellular Biochemistry Supplement. 22: 181-187. https://doi.org/10.1002/jcb.240590823

Crozier, A., Jaganath, I.B., and Clifford, M.N. 2009. Dietary phenolics: chemistry, bioavailability and effects on health. Natural Product Reports. 26: 1001-1043. https://doi.org/10.1039/B802662A

Donkor, O.N., and Shah, N.P. 2008. Production of beta-glucosidase and hydrolysis of isoflavone phytoestrogens by Lactobacillus acidophilus, Bifidobacterium lactis, and Lactobacillus casei in soymilk. Journal of Food Science. 73: 15-20. https://doi.org/10.1111/j.1750-3841.2007.005 47.x

Fan, J.P., Jing, C., Xue, H.Z., Jun, Z.H., Tao, K., Sheng, T., Zhe, T., Yan, L.X., Rui, X., and Jian, H.Z. 2012. Optimization of ionic liquid based ultrasonic assisted extraction of puerarin from Radix Puerariae Lobatae by response surface methodology. Food Chemistry. $135: 2299-2306$. https://doi.org/10.1016/j.foodchem.2012.07.038

Fujita, A., Alencar, S.M., and Park, Y.K. 2010. Conversion of isoflavone glucosides to aglycones by partially purified $\beta$-glucosidases from microbial and vegetable sources. Applied Biochemistry and Biotechnology. 10: 12010-12015. https://doi.org/10.1007/s12010-0151668-1

Han, K.K., Soares, JM. Jr., Haidar, M.A., Rodrigues de Lima, G., and Baracat, E.C. 2002. Benefits of soy isoflavone therapeutic regimen on menopausal symptoms. Obstetrics and Gynecology. 99: 389-394.

Horii, K., Adachi, T., Matsuda, T., Tanaka, T., Sahara, H., Shibasaki, S., Ogino, C., Hata, Y., Ueda, M., and Kondo, A. 2009. Improvement of isoflavone aglycones production using beta-glucosidase secretory produced in recombinant Aspergillus oryzae. Journal of Molecular Catalysis B: Enzymatic. 59: 297-301. https://doi.org/10.1016/j.molcatb. 2008.11.013

Ismail, B., and Hayes, K. 2005. Beta-glycosidase activity toward different glycosidic forms of isoflavones. Journal Agricultural and Food Chemistry. 53: 4918-4924. https://doi.org/10.1021/jf0404694

Izumi, T., Piskula, M.K., Osawa, S., Obata, A., Tobe, K., Saito, M., Kataoka, S., Kubota, Y., and Kikuchi, M. 2000. Soy isoflavone aglycones are absorbed faster and in higher amounts than their glucosides in humans. The Journal of Nutrition. 130: 1695-1699. https://doi.org/10.1093/jn/ 130.7.1695 
Klejdus, B., Mikelova, R., Adam, V., Zehnalek, J., Vacek, J., Kizek, R., and Kuban, V. 2005. Liquid chromatographic-mass spectrometric determination of genistin and diadzin in soybean food samples after accelerated solvent extraction with modified content of extraction cell. Analytica Chimica Acta. 517: 1-11. https://doi.org/10.1016/j.aca.2004. 05.003

Kuo, L.C., and Lee, K.T. 2008. Cloning, expression, and characterization of two beta-glucosidases from isoflavone glycoside-hydrolyzing Bacillus subtilis natto. Journal of Agricultural and Food Chemistry. 56: 119-125. https://doi.org/10.1021/jf072287q

Kuo, L.C., Cheng, W.Y., Wu, R.Y., Huang, C.J., and Lee, K.T. 2006. Hydrolysis of black soybean isoflavone glycosides by Bacillus subtilis natto. Applied Microbiology and Biotechnology. 73: 314-320. https://doi.org/ 10.1007/s00253-006-0474-7

Luciana, C.G., Amanda, A.M., Geni, S.V., José, M., Gontijo M., Josemeyre, B.S., Elza, I.I., and Mara, Lúcia, L.R. 2014. Soybean $\beta$-glucosidase immobilisated on chitosan beads and its application in soy drink increase the aglycones. Brazilian Archives of Biology and Technology. 57: 766-773. http://dx.doi.org/10.1590/S1516-8913201402331

Mauricio, A.R., Miguel, P., and Carmelo, G.B. 2003. Ultrasound-assisted extraction of soy isoflavones. Journal of Chromatography A. 1012: 119-128. https://doi.org/10.1016/S0021-9673(03)01184-1

Murphy, P.A. 1982. Phytoestrogen content of processed soybean products. Food Technology. 36: 60-64.

Nahas, E.P., Jorge, N.N., Laurival, D.L., Paulo, T., Anaglória, P., and Ivete, D. 2004. Benefits of soy germ isoflavones in postmenopausal women with contraindication for conventional hormone replacement therapy. Maturitas. 48: 372-380. https://doi.org/10.1016/j.maturitas.2003.09.026

Ohta, A., Uehara, M., Sakai, K., Takasaki, M., Adlercreutz, H., Morahashi, T., and Ishimi, Y. 2002. A combination of dietary fructooligosaccharides and isoflavone conjugates increases femoral bone mineral density and equal production in ovariectomized mice. The Journal of Nutrition. 132: 2048-2054. https://doi.org/10.1093/jn/132.7.2048

Park, K.-Y., Jung, K.-O., Rhee, S.-H., and Choi, Y. H. 2003. Antimutagenic effects of doenjang (Korean fermented soypaste) and its active compounds. Mutation Research/Fundamental and Molecular Mechanisms of Mutagenesis. 523: 43-53. https://doi.org/10.1016/S00275107(02)00320-2 
Phongphisutthinant, R., Wiriyacharee, P., Preunglampoo, S., Leelapat, P., Kanjanakeereetumrong, P., and Lumtong, S. 2015. Selection of Bacillus spp. for isoflavone aglycones Enriched Thua-nao, a traditional Thai fermented soybean. Journal of Pure and Applied Microbiology. 9: 59-68.

Rostagno, M.A., Julio, M.A., and Sandi, D. 2002. Supercritical fluid extraction of isoflavones from soybean flour. Food Chemistry. 78: 111-117. https://doi.org/10.1016/S0308-8146(02)00106-1

Sarkar, P., Hasenack, B., and Nout, M. 2002. Diversity and functionality of Bacillus and related genera isolated from spontaneously fermented soybeans (Indian Kinema) and locust beans (African Soumbala). International Journal of Food Microbiology. 77: 175-186. https:// doi.org/10.1016/S0168-1605(02)00124-1

Seung, Y.C., Yu, N.L., and Hyun, J.P. 2010. Optimization of ethanol extraction and further purification of isoflavones from soybean sprout cotyledon. Food Chemistry. 117: 312-317. https://doi.org/10.1016/j.foodchem.2009. 04.003

Song, X., Xue, Y., Wang, Q., and Wu, X. 2011. Comparison of three thermostable $\beta$-glucosidases for application in the hydrolysis of soybean isoflavone glycosides. Journal of Agricultural and Food Chemistry. 59: 1954-1961. https://doi.org/10.1021/jf1046915

Wiriyacharee, P., Sakda, P., Rewat, P., Posri, L., and Patthama, K. 2011. Isoflavones (Daidzein and Genistein) Production from Biobean, $1^{\text {st }}$ phase. Science and Technology Research Institute of Chiang Mai University.

Wiriyacharee, P. 2012. Experimental Design. Faculty of Agro-Industry. Chiang Mai University.

Wiriyacharee, P., Sakda, P., Rewat, P., Posri, L., and Supakit, C. 2012. Isoflavones (Daidzein and Genistein) Production from Biobean, $2^{\text {nd }}$ phase. Science and Technology Research Institute Chiang Mai University.

Xue, Y., Yu, J., and Song, X. 2009. Hydrolysis of soy isoflavone glycosides by recombinant beta-glucosidase from hyperthermophile Thermotoga maritima. Journal of Industrial Microbiology. 36: 1401-1408. https:// doi.org/10.1007/s10295-009-0626-8

Yang, L., Ning, Z.S., Shi, C.Z., Chang, Z.Y., and Huan, L.Y. 2004. Purification and characterization of an isoflavone-conjugates hydrolyzing beta-glucosidase from endophytic bacterium. Journal of Agricultural and Food Chemistry. 52: 1940-1944. https://doi.org/10.1021/jf030476c 
Yang, S., Wang, L., Yan, Q., Jiang. Z., and Li, L. 2009. Hydrolysis of soybean isoflavone glycosides by a thermostable betaglucosidase from Paecilomyces thermophila. Food Chemistry. 115: 1247-1252. https:// doi.org/10.1021/jf030476c

Yue, X., Abdallah, A.M., and Xu, Z. 2009. Distribution of isoflavones and antioxidant activities of soybean cotyledon, coat and germ. Journal of Food Processing and Preservation. 34: 795-806. https://doi.org/10.1111/ j.1745-4549.2009.00395.x

Zehranur, Y., Berat, C.A., Belma, A., and Ummugulsum, T. 2017. $\beta$-Glucosidase activity and bioconversion of isoflavone glycosides to aglycones by potential probiotic bacteria. International Journal of Food Properties. 20: 2878-2886. https://doi.org/10.1080/10942912.2017.1382506 